\title{
Vanilla Landscapes: Meaning, Memory, and the Cultivation of Place in Madagascar. By Sarah R. Osterhoudt. 2017. NYBG Press, Bronx, NY. 180 pp.
}

\author{
Terese Gagnon $^{1^{*}}$ \\ ${ }^{1}$ Department of Anthropology, Syracuse University, Syracuse, USA. \\ *tvgagnon@syr.edu
}

Received July 30, 2018

OPEN ӘACCESS

Accepted September 16, 2018

DOI 10.14237/ebl.9.2.2018.1365

Copyright (c) 2018 by the author(s) licensee Society of Ethnobiology. This is an open-access article distributed under the terms of the Creative Commons Attribution-NonCommercial 4.0 International Public License (https://creativecommons.org/licenses/by-nc/4.0), which permits non-commercial use, distribution, and reproduction in any medium, provided the original author and source are credited.

Here Sarah Osterhoudt writes about memoryindividual and collective, pleasant and troubled-as narrated by residents of Imorona, Madagascar through the elements of local landscapes, trees and plants. Osterhoudt is an assistant professor of anthropology at Indiana University. Her relationship with smallholder farmers in Madagascar began in 2005 as a Peace Corps volunteer. She later returned to conduct research in anthropology and economic botany, focusing on the social dimensions of agroecological landscapes, the subject of this monograph.

The book opens with a vignette about an experience Osterhoudt had relatively early on in her time in Imorona. She was brought to an agroforestry field where the vanilla flowers had just begun to bloom and was instructed by an elder to "look!" at a single flower. Vanilla is the most important cash crop of the area. Upon regarding the man's expressionone of wonder-she realized that she "was not seeing the same flower that he was seeing" (p. 3). Her study in many ways is a journey leading up to the moment several years later when she again looks at a vanilla flower and is able to "see it," not in exactly the same way her consultant, Papa Armand saw it, but with a transformed view.

This is achieved through countless hours spent with consultants in agroforestry fields and in other locations, listening to the stories evoked by aspects of the landscape such as the life event that a particular tree marks or the legacies of colonialism and resistance recalled by the rocks on a certain beach. She comes to understand the importance of these elements, including the central vanilla flower, as being symbolic and sensory portals into the histories of peoples' lives and of the community, spanning not only annual cycles of cultivation but also generations. This addresses her multi-layered research questions that ask how people at once cultivate crops, meaning, and memories within their agroforestry fields and also why traditional farming systems and ecological diversity have persisted in this place while they have faded in surrounding areas.

This is a truly interdisciplinary work encompassing multiple methodologies and theoretical perspectives. No doubt, this is in part a reflection of Osterhoudt's training from the Yale combined $\mathrm{PhD}$ program in Anthropology and Forestry and Environmental Studies, additionally paired with a joint degree from The New York Botanical Garden. Osterhoudt states that part of her mission is to further integrate perspectives from anthropology, such as humanistic studies of memory and power, with the technical work of research in economic botany. This is an important task, though not an easy one.

At times, it feels as though the two perspectives are working in different directions in the text. The ethnographic portion appears mostly in the first half of the book while the botanical data and analysis is mostly in the second. Osterhoudt comments on this decision, saying that she initially sought to integrate the two but that the result was unsatisfactory to her. Thus, she separated them, conceptualizing the successive approaches as "landscape fugues," drawing on a musical metaphor: a subject introduced in one part and taken up by another part with interweaving 
elements (p. 61). While I appreciate the challenge of integrating such material, I could not help feeling disappointed that in the final form the two approaches run mostly parallel rather than mingling to productively trouble the waters of the respective traditions. There is great potential for innovative insight in bringing these two modes of inquiry further into dialogue and Osterhoudt is in a special position to deliver it.

That said, the skill and knowledge required to approach the field as both a cultural anthropologist and an economic botanist are truly impressive. And Osterhoudt does bring her perspective from one to bear on the other. She does this, for example, by identifying the importance of plants as mediators of social life and history for residents of Imoronasomething another anthropologist may have missedand by addressing critiques of both methodological practices, such as what Latour would call the "black box" of scientific knowledge production (Latour 1988). Her main thesis is that the capacity of plants to hold various meanings and evoke memories for people may be a central reason for the persistence of ecological diversity, alongside economic and historic factors.

Furthermore, Osterhoudt engages with the ontological turn but does so differently than many others. In contrast to ontological writers who spill much ink mulling complex theories of personhood but provide relatively little grounded evidence to support them, Ousterhoudt's approach is refreshingly rooted. She and her colleagues in Imorona carefully measure trees, calculate diversity indices in farmers' agroforestry vanilla fields, and meticulously catalogue 97 tree species and 73 herbaceous species, including information on local names and uses. For these reasons her work will likely be both familiar and of interest to ethnobiologists, particularly those concerned with Madagascar or agroforestry generally. Because the vanilla crop she discusses is grown through agroforestry and sold as a valuable export, this study may be particularly useful to those interested in relationships between biodiversity, traditional agricultural practices, and the global market.

This work provides impressively rich data and grounded insights about the diverse trees and plants grown in agroforestry fields, as well as about human social life and history in the area. If the up-close view of agro-ecology delivered in the form of charts and graphs could be further integrated with theoretical conclusions about the memories and meanings contained in plants, in the form of greater and more detailed ethnographic descriptions, then the outcome would be even more groundbreaking than it already is. I hope many will follow Osterhoudt's lead so that scholars and their audiences may increasingly come to see plants with changed eyes, as Osterhoudt describes is the outcome of years of apprentice with her colleagues in Imorona. That is, as radically connected to humans and their life projects.

\section{References Cited}

Latour, B. 1988. Science in Action: How to Follow Scientists and Engineers through Society. Harvard University Press, Cambridge, MA. 